\title{
Additions of Glutathione or Specific Glutathione-rich Dry Inactivated Yeast Preparation (DYP) to Sauvignon blanc Must: Effect on Wine Chemical and Sensory Composition
}

\author{
M. Gabrielli ${ }^{1}$ J.L. Aleixandre-Tudo ${ }^{2}$, P.A. Kilmartin² ${ }^{3}$ N. Sieczkowski ${ }^{4}$, W.J. du Toit ${ }^{*}$
}

(1) Department of Food, Environmental and Nutritional Sciences, Università degli Studi di Milano, Via G. Celoria 2 , 20133 Milano, Italy

(2) Department of Viticulture and Oenology, Stellenbosch University, Private Bag X1, Matieland, 7602, South Africa

(3) Wine Science Programme, School of Chemical Sciences, The University of Auckland, Private Bag 92019, Auckland, New Zealand

(4) Lallemand SAS, R\&D Oenology Division, 31700 Blagnac, France

Submitted for publication: June 2016

Accepted for publication: October 2016

Key words: Sauvignon blanc, glutathione, inactivated yeast, aroma, sensory analysis

\begin{abstract}
Although the addition of pure glutathione (GSH) is not allowed under current regulations, the concentration of this compound can be increased in wine through the addition of glutathione-enriched dry yeast preparations (DYP). These preparations have been observed to have antioxidant properties and could thus influence wine aroma and sensory characteristics. The main aim of this study was to investigate the effect of DYP and GSH juice additions on the sensory and chemical composition of Sauvignon blanc wine. Four juice additions were performed and compared against a control treatment: $5.5 \mathrm{mg} / \mathrm{L} \mathrm{of} \mathrm{GSH}$; 0.4 g/L of DYP; $80 \mathrm{mg} / \mathrm{L}$ of GSH; $0.4 \mathrm{~g} / \mathrm{L}$ of DYP plus $80 \mathrm{mg} / \mathrm{L}$ of GSH. After three months of bottling, the volatile and sensorial composition was investigated. The addition of DYP preparations to must increased the concentration of certain wine volatile compounds, with increased attributes of riper tropical fruit aromas, which was not always observed with the GSH additions. The addition of DYP influenced the concentrations of some volatile compounds, which modified the white wine aroma. The release of compounds other than GSH by the yeast products is proposed as the reason for these changes. The results observed in this study can assist winemakers to modify the aroma profile of Sauvignon blanc wines.
\end{abstract}

\section{INTRODUCTION}

The tripeptide L-glutamyl-L-cysteinyl-glycine, or glutathione (GSH), is the major low-molecular-mass thiol compound in plants and animals (Kritzinger et al., 2013a). GSH plays an important role in the biosynthesis of many aroma precursors present in the berries of several cultivars. An example of this is given by the varietal's thiol compounds that contribute to typical Sauvignon blanc aromas of flower, boxwood, blackcurrant (mercapto-4-methylpentan-2one, 4MMP), citrus, guava and passion fruit (3-mercaptohexan-1-ol, 3MH, 3-mercaptohexyl acetate, 3MHA), which originate from the precursors [S-3-(hexan-1-ol)-L-cysteine, S-4-(4-methylpentan-2-one)-L-cysteine, [S-3-(hexan-1-ol)glutathione and S-4-(4-methylpentan-2-one)-glutathione (Coetzee \& Du Toit, 2012). GSH conjugates are thus found in the juice and can be a source of the aroma compounds in the wines (Fedrizzi et al., 2009; Roland et al., 2010). The concentration of GSH in grapes and juice depends on the cultivar and climatic conditions. Lavigne-Cruege and
Dubourdieu (2002) reported GSH levels in different white cultivars to be between 17 and $114 \mathrm{mg} / \mathrm{kg}$ (56 to $372 \mu \mathrm{mol} /$ $\mathrm{kg}$ ). The GSH content in grape juice is influenced by factors such as exposure to oxygen, tyrosinase activity and grape skin maceration during pre-fermentation (Cheynier et al., 1989; Du Toit et al., 2007), with reported ranges varying from 10 to $100 \mathrm{mg} / \mathrm{L}$ (Cheynier et al., 1989). Additionally, several authors have reported conflicting results on the trend of GSH during alcoholic fermentation (Du Toit et al., 2007; Andujar-Ortiz et al., 2012; Kritzinger et al., 2013b). The concentration of GSH in wine is lower than in the juice and grapes, and values from 1 to $20 \mathrm{mg} / \mathrm{L}$ typically are found (Du Toit et al., 2007). Saccharomyces cerevisiae can also affect GSH content in wine during alcoholic fermentation and lees ageing (Kritzinger et al., 2013b), with a maximum reported increase of around $20 \mathrm{mg} / \mathrm{L}$ for a particular yeast strain (Lavigne-Cruege et al., 2007).

The biological importance of GSH is due to the

*Corresponding author: wdutoit@sun.ac.za

Acknowledgements: The experimental work reported here was a project supported financially by Lallemand and THRIP. The authors gratefully acknowledge Neil Ellis Wines, which provided the Sauvignon blanc juice 
nucleophilic and reducing properties of the thiol group in the cysteine residue (Elskens et al., 1991). GSH is involved in many vital functions of $S$. cerevisiae, such as maintaining the integrity of mitochondrial membranes, responding to oxidative stress, xenobiotics and endogenous toxic metabolite detoxification, and responding to deficiencies in sulphur and nitrogen (Penninckx, 2002; Tominaga \& Dubourdieu, 2003). Moreover, GSH plays an important role in the oxidative phenomena of white musts and wines. Enzymatic oxidation occurs in musts and is correlated with the amounts of hydroxycinnamic acid esters (caftaric acid and coutaric acid) and flavan-3-ols (Li et al., 2008). Phenolic compounds, particularly those with an ortho-diphenol group, are mainly responsible for oxidative browning (BetésSaura et al. 1996). The reaction involves the oxidation of catechols to form unstable quinones, which are responsible for the wine browning (Oliveira et al., 2011). GSH limits this phenomenon through the trapping of the unstable quinone molecule (Cheynier et al., 1990; Rigaud et al., 1991). GSH has also been proposed as an alternative antioxidant to $\mathrm{SO}_{2}$ that potentially could lead to a decrease in the required sulphur levels in finished wines (Makhotkina et al., 2014).

In addition, exposure to oxygen during white wine ageing can profoundly change the colour and aromatic profile of a wine (Simpson, 1978). In a young wine, the oxidative degradation of volatile compounds leads to a loss in fruity and floral aromas. Moreover, it has been reported that, in cases where the concentration of GSH in white wine exceeds 6 to $10 \mathrm{mg} / \mathrm{L}$, both colour and aroma were better preserved during ageing and storage (Lavigne-Cruege \& Dubourdieu, 2004). A number of authors have reported a positive effect of GSH against the oxidation of varietal thiols during the ageing and storage of white wine (Blanchard et al., 2004; Dubourdieu \& Lavigne-Cruege, 2004; Ugliano et al., 2011, Coetzee \& Du Toit 2012; Coetzee et al., 2013).

Despite the observed effects of GSH in wine, the addition of GSH prior to bottling was recently approved by the OIV, as long as doses are never higher than $20 \mathrm{mg} / \mathrm{L}$ (OIV, 2015). In addition, GSH can be added to the must or wine through the addition of other permitted additives (DYP), which allow the amount of GSH to be increased (Pozo-Bayón et al., 2009; OIV, 2013). DYPs are manufactured from the thermal inactivation of $S$. cerevisiae cultivated under specific conditions in which the intra-cellular accumulation of GSH is stimulated (Kritzinger et al., 2013a). In the work of PozoBayón et al., (2009), four classification categories for DYPs were proposed: inactive yeast, yeast autolysates, yeast hulls or walls, and yeast extracts. The products referred to as GSH-rich inactivated dry yeast preparations (DYPs) are added during alcoholic fermentation and are expected to increase the wine GSH content, either by the liberation of GSH into the wine, or by allowing the yeast to assimilate GSH precursors during alcoholic fermentation (Kritzinger et al., 2012). The addition of DYPs has been recommended by the producers in order to prevent aroma and colour losses and to increase the availability of fermentative nutrients in wines (Pozo-Bayón et al., 2009). Andujar-Ortíz et al. (2012) and Kritzinger et al. (2012) reported an increase in the concentration of GSH after the addition of DYPs to Grenache and Sauvignon blanc juice. Moreover, Andujar-
Ortíz et al. (2014) reported an increase in the intensity of typical fruity attributes (banana, strawberry) in young Grenache rosé wines made after the addition of DYPs. These authors suggest that the GSH released from DYP could have caused a protective effect against the oxidation of wine aroma compounds. Other authors have also observed the protection of white and rosé wines against oxidation after the addition of a specific GSH-enriched inactivated DYP during alcoholic fermentation. Better protection of the chromatic and organoleptic properties, as well as a higher presence of some of the particular volatile thiols, was observed (Aguera et al., 2012).

The evolution of the GSH content in GSH- or DYPsupplemented must during the fermentation process currently is poorly investigated. It is also not well known whether changes brought about in the sensorial and volatile composition of wines treated with DYPs are due to the GSH contained in these products or to other constituents being released into the must or wine. The aim of this work was thus to study the levels of extracellular GSH during alcoholic fermentation after the addition of different dosages of pure GSH, or by adding varying concentrations of a specific glutathione-rich inactivated dry yeast preparation (DYP). Moreover, the study also reports and discusses the influence of GSH and DYP additions on the volatile composition and sensory characteristics of Sauvignon blanc white wines.

\section{MATERIALS AND METHODS \\ Chemicals and reagents}

The organic yeast rehydration nutrient (GO-FERM PROTECT EVOLUTION ${ }^{\mathrm{TM}}$ ) and the specific GSH-rich inactivated yeast (OPTI-MUM WHITE EVOLUTION ${ }^{\mathrm{TM}}$ (DYP)) were obtained from Lallemand Blagnac, France. $\mathrm{N}_{2}$ gas and $\mathrm{CO}_{2}$ gas were purchased from Afrox, Cape Town, South Africa. Ascorbic acid, sulphur dioxide as $\mathrm{K}_{2} \mathrm{~S}_{2} \mathrm{O}_{5}$, methanol, reduced GSH, formic acid, acetonitrile, tris-EDTA, meta-phosphoric acid, ethanol, sodium sulphate anhydrous, $p$-hydroxymercurybenzoate, butylated hydroxyanisole, dichloromethane and diethyl ether were purchased from Sigma Aldrich (St Louis, MI, USA). Standards for the quantification of esters, alcohols, fatty acids and terpenes were also obtained from Sigma Aldrich. HPLC-grade water was obtained from a Milli-Q system (Millipore Filter Corp., Bedford, MA).

\section{Juice and winemaking treatments}

Clear Sauvignon blanc juice (2013 vintage, $22.5^{\circ} \mathrm{Brix}$, $\mathrm{pH}$ 3.3 and total acidity $5.5 \mathrm{~g} / \mathrm{L}$ ) was collected from Neil Ellis Wines, based in Stellenbosch, and divided into $10 \mathrm{~L}$ stainless steel canisters. Nitrogen in gas form was blown inside the canisters to replace oxygen before juice transfer. The juice was divided into five treatments: the control $(\mathrm{C})$, and additions of $5.5 \mathrm{mg} / \mathrm{L}$ of GSH (GSH 5.5), $80 \mathrm{mg} / \mathrm{L}$ of GSH (GSH 80), $0.4 \mathrm{~g} / \mathrm{L}$ of DYP (DYP), and $80 \mathrm{mg} / \mathrm{L}$ of GSH plus $0.4 \mathrm{~g} / \mathrm{L}$ of DYP (DYP+GSH 80). DYP was added at levels according to Lallemand's recommendation (DYP treatment). Finally, the maximum dose of GSH was combined with DYP addition at $0.4 \mathrm{~g} / \mathrm{L}$ to investigate a possible synergistic effect. An aliquot of the juice was used to ensure complete dissolution of the GSH or DYP additions into the juice matrix. Treatments 
were supplemented just before yeast inoculation according to the supplier's recommendations (www.lallemand.com). Three fermentation replicates per treatment were performed. The yeast strain Saccharomyces cerevisiae LALVIN ${ }^{\circledR}$ QA23 (Lallemand) was rehydrated in GO-FERM PROTECT EVOLUTION $^{\mathrm{TM}}$ at $0.3 \mathrm{~g} / \mathrm{L}$ (Lallemand) and inoculated into the juice at $0.3 \mathrm{~g} / \mathrm{L}$. Fermentation took place under controlled temperature at $15^{\circ} \mathrm{C}$. The progress of fermentation was monitored by measuring weight loss. At the end of fermentation, when no more weight loss had occurred for three consecutive days, $60 \mathrm{mg} / \mathrm{L}$ of sulphur dioxide was added to all the treatments and the wines were stored at $-4^{\circ} \mathrm{C}$ for ten days to carry out tartrate stabilisation. The wine was then racked with $\mathrm{N}_{2}$ from the yeast lees and bottled in green $750 \mathrm{~mL}$ screw-cap wine bottles under $\mathrm{CO}_{2}$ gas.

\section{Standard winemaking analyses}

Routine wine analyses were performed after alcoholic fermentation (residual reducing sugar, total acidity (TA), alcohol, volatile acidity (VA), malic acid and $\mathrm{pH}$ ) using a Grapescan $^{\mathrm{TM}}$ FT 120 instrument (Foss Electric, Denmark).

\section{Sampling procedure}

Samples destined for UPLC-MS/MS analyses were taken just after the juice was collected in the $10 \mathrm{~L}$ stainless steel canisters. The sampling was carried out before and after the addition of DYP and GSH, and at difference stages throughout the fermentation, namely after 25\%, 50\%, 75\% and $100 \%$ completion of alcohol fermentation. Twenty $\mathrm{mL}$ of juice were transferred from the canisters into $20 \mathrm{~mL}$ plastic vials. To completely inhibit residual phenol oxidase or laccase activity, $\mathrm{SO}_{2}$ and ascorbic acid is raised to $1000 \mathrm{mg} / \mathrm{L}$ and $500 \mathrm{mg} / \mathrm{L}$ respectively. The plastic vials were saturated with $\mathrm{CO}_{2}$ before and after the juice was transferred into the vials. Additional $\mathrm{CO}_{2}$ was blown over the headspace, and the vials were sealed hermetically. The vials were then frozen at $-20^{\circ} \mathrm{C}$ until analysis. The analysis of aroma compounds and sensory analysis were performed three months after bottling.

\section{Preparation of glutathione samples}

Samples $(4 \mathrm{~mL})$ were thawed and centrifuged (Centrifuge 5415 D, Eppendorf, Hamburg, Germany) at $1600 \mathrm{rpm}$ for $5 \mathrm{~min}$ at $20^{\circ} \mathrm{C}$. The supernatant was then diluted five times with a solution containing $1000 \mathrm{mg} / \mathrm{L}$ of $\mathrm{SO}_{2}$ and $500 \mathrm{mg} / \mathrm{L}$ of ascorbic acid. Finally, the samples were filtered through a $0.45 \mu \mathrm{m}$ syringe filter and injected onto the UPLC-MS/MS instrument (Kritzinger et al. 2012).

\section{Quantification of reduced GSH released from the specific glutathione-rich inactivated yeast (DYP)}

The GSH levels released from the DYP were evaluated in a model solution consisting of $5 \mathrm{~g} / \mathrm{L}$ of tartaric acid adjusted to $\mathrm{pH} 3.3$ with $1 \mathrm{M} \mathrm{NaOH}$. In order to decrease oxygen in the model solution, $\mathrm{N}_{2}$ gas was bubbled for 30 min prior to DYP addition, after which $0.4 \mathrm{~g}$ of DYP was added to $100 \mathrm{~mL}$ of model solution and stirred for $10 \mathrm{~min}$. A sample was then drawn and injected within the next half an hour. The quantification was performed in triplicate.

\section{Glutathione analysis}

GSH concentrations were determined using an UPLC-MS/ MS method described by Kritzinger et al. (2012). A Waters Acquity UPLC (Milford, MA, USA) connected to a Waters Xevo triple-quadrupole mass spectrometer was used for GSH quantification. The separation was achieved using a Waters Acquity BEH phenyl column (100 mm x $2.1 \mathrm{~mm}$ x $1.7 \mu \mathrm{m})$. For solvents A and B, $0.4 \%$ trifluoroacetic acid and acetonitrile were used respectively. Solvent gradient has been reported elsewhere (Kritzinger et al., 2012). A cone voltage of $18 \mathrm{~V}$ in combination with a multiple reaction monitoring transition of $308.1>179.1$ at a collision energy of $17 \mathrm{eV}$ was used as optimised setting. The injection volume was $3 \mu \mathrm{L}$ and a dilution of five times in water was used to achieve the best accuracy.

\section{Thiol analysis}

Thiol compounds were analysed using the extraction method reported by Tominaga et al. (1998), with some modifications as reported by Coetzee et al. (2013). Initially, $5 \mathrm{~mL}$ of $1 \mathrm{mM}$ $p$-hydroxymercurybenzoate ( $p$-HMB), and then $0.5 \mathrm{~mL}$ of $2 \mathrm{nM}$ butylated hydroxyanisole (BHA) solution, were added to $50 \mathrm{~mL}$ of wine. After stirring, $50 \mu \mathrm{L}$ of a deuterated internal standard solution (supplied by Auckland University, New Zealand) containing $22 \mathrm{mM}$ of 3-mercapto-hexanol (3MH), $2.8 \mathrm{mM}$ of 3-mercapto-hexyl acetate (3MHA) and $2.5 \mathrm{nM}$ of 4-methoxy-2-methyl-2-mercaptobutane (4M2M2SB) used to quantify 4-mercapto-4-methylpentan-2-one (4MMP) was incorporated into the wine. This was followed by the injection of $2 \mu \mathrm{L}$ of a concentrated sample onto an Agilent Gas Chromatograph 6890N coupled to an Agilent 5973 mass-selective detector (Agilent, Santa Clara, CA, USA). A HP-Innowax column (60 m x $252 \mu \mathrm{m} \times 0.25 \mu \mathrm{m})$ with helium as carrier gas was used for compounds separation. Flow rates, oven temperatures and standard curves used for thiol quantification have been reported elsewhere (Coetzee et al., 2013).

\section{Ester, alcohol, fatty acid and terpene analyses}

Ester, alcohol and fatty acid concentrations were determined using the GC-Flame ionisation detector (FID) method described by Coetzee et al. (2013). The volatile compounds were extracted from the wine $(5 \mathrm{~mL})$ using a liquid-liquid extraction by sonicating the diethyl ether $(1 \mathrm{~mL})$ wine mixture for $5 \mathrm{~min}$. 4-Methyl-2-pentanol $(100 \mu \mathrm{L}$ of $0.5 \mathrm{mg} / 1$ solution in a $12 \%$ ethanol-water mixture) was used as internal standard. The mixture was then centrifuged at 4000 RPM for $3 \mathrm{~min}$ before the ether layer was removed and dried by adding $\mathrm{Na}_{2} \mathrm{SO}_{4}$. The extracts were injected in duplicate in a Agilent 6890 Plus GC (Little Falls, Wilminghton, DE, USA) equipped with a split/splitless injector and FID detector using a J\&W DB-FFAP capillary GC column (Agilent, Little Falls, Wilmington, DE, USA) with the following dimensions: $60 \mathrm{~m}$ x $0.32 \mathrm{~mm}$ x $0.5 \mu \mathrm{m}$. A $15: 1$ split ratio was used, with a split flow rate of $49.5 \mathrm{~mL} / \mathrm{min}$ and a column flow rate of $3.3 \mathrm{~mL} / \mathrm{min}$ using hydrogen as a carrier. Method validation, quantification as well as separation conditions have been reported elsewhere (Coetzee et al., 2013).

Monoterpene analysis was performed following a solid phase extraction in a Visiprep SPE vacuum manifold 20- 
port model from Supelco (Bellefonte, Pennsylvania, USA). A volume of $50 \mu \mathrm{l}$ of 2,6-dimethyl-6-hepten-2-ol $(25 \mathrm{mg} / \mathrm{L}$ in ethanol) was used as internal standard and was added to $50 \mathrm{~mL}$ of wine. Dichloromethane $(4 \mathrm{~mL})$, methanol $(4 \mathrm{~mL})$ and, finally, a $12 \%$ ethanol-water solution $(4 \mathrm{~mL})$ were used to condition the cartridges (Strata SDB-L; Phenomenex, Torrance, CA, USA). Vacuum suction was used to rinse the wine through the cartridge, and $4 \mathrm{~mL}$ of Milli-Q-Water were later used to clean the cartridges. Samples were then dried under vacuum for $15 \mathrm{~min}$. Finally, dichloromethane ( $2 \mathrm{~mL}$ ) was used to elute the terpenic compounds from the cartridge. Sodium sulphate crystals were added to remove any traces of water. Each sample was injected in duplicate in splitless mode on a Hewlett-Packard (Palo Alto, CA, USA) 5890 Series II gas chromatograph equipped with a $60 \mathrm{~m} \times 0.32 \mathrm{~mm} \times 0.5 \mathrm{~mm}$ fused DB-FFAP capillary column (J\&W Scientific, Folsom, CA, USA), and FID. Separation conditions have been reported elsewhere (Coetzee et al., 2013) and quantification was done by comparison with a calibration curve of pure standards.

\section{Sensory analysis}

Wines corresponding to the different treatments were analysed by means of general descriptive sensory analysis (DA). A trained panel consisted of two males and eight females, with ages ranging from 22 to 65 years old (with an average age of 40.1). Panellists were trained three times a week. Each training session lasted two hours, with a 15-minute break. The first three training sessions were used to establish the lexicon needed to describe the wines. During the first training session, the five wines were presented and the panel was asked to generate sensory attributes to describe them. A list of attributes was compiled and the corresponding reference standards were prepared and presented in the following session. The list of attributes used to describe the set of wines was reduced from 21 attributes to 13 by means of discussion amongst the panellists during the following two training sessions (Table 1). The last four training sessions were used to establish consensus amongst the panellists with regard to the attributes and the wines' ratings on a $10 \mathrm{~cm}$ line scale anchored at none on the left-hand side and intense on the right-hand side. Although a $10 \mathrm{~cm}$ line scale was used, the results of the data analysis are expressed out of 100 . The wines were evaluated by the panellists in triplicate on the same day. Panellists were forced to take breaks longer than 10 minutes between replicates. The sensory evaluation was conducted in off-white tasting booths located in a sensory laboratory. The sensory laboratory was quiet, odour free and had controlled air conditioning $\left(20 \pm 2^{\circ} \mathrm{C}\right)$. Twenty-five millilitres of each wine sample were presented in black ISO tasting glasses covered with petri dishes coded with pseudo random three-digit codes generated by an online research randomiser. In order to limit biases, each panellist received the samples in a different order according to a balanced Williams Latin square design, computed using the design of experiments (DOE) function of the MX package of XLSTAT (Microsoft, Redmond, WA, USA). Data was captured on paper ballots, line scales were measured with rulers and data was captured using Microsoft Excel 2010 (Microsoft, Redmond, WA, USA).

Panel performance was assessed using the workflow suggested by Tomic et al. (2010). Repeatability ( $p^{*} \mathrm{MSE}$ plots and $F$-plots), discriminability and panel consensus (Tucker-1) were tested using PanelCheck 1.4 (Nofima Mat, Tromsø, Norway). DA data was analysed by means of twoway ANOVA with panellists and wine samples as main effects. Wine sample effect was tested by the regular $F$ test to identify significant $(\mathrm{p}<0.05)$ attributes. Only significant attributes were used for further statistical analysis. Principal component analysis (PCA) was conducted on the correlation matrix of the average intensity scores to obtain a multivariate sensory map of the DA data.

\section{Data analysis}

After quantification, descriptive statistical measurements, including mean and standard deviation, were calculated using Microsoft Excel 2007 (Microsoft Corporation, www.microsoft.com). ANOVA was performed with

\section{TABLE 1}

Sensory attributes and corresponding reference standards used during general descriptive sensory analysis training.

\begin{tabular}{ll}
\hline Attribute & Reference standard composition \\
\hline Fresh pineapple $^{\mathrm{a}, \mathrm{c}}$ & three $1 \mathrm{~cm}^{2}$ pieces of fresh pineapple \\
Ripe pineapple ${ }^{\mathrm{a}, \mathrm{c}}$ & three $1 \mathrm{~cm}^{2}$ pieces of canned pineapple (Koo) \\
Fresh tropical $^{\mathrm{b}}$ & $30 \mathrm{~mL}$ of tropical fruit juice (Ceres), $5 \mathrm{~mL}$ fresh homogenised pineapple supernatant \\
Canned tropical $^{\mathrm{b}}$ & $30 \mathrm{~mL}$ tropical fruit juice (Ceres), $5 \mathrm{~mL}$ canned guava syrup (Koo) \\
Green guava $^{\mathrm{b}}$ & one $2 \mathrm{~cm}^{2}$ piece of guava with a green skin \\
Ripe guava & one $2 \mathrm{~cm}^{2}$ piece of guava with a yellow/pink skin \\
Grapefruit ${ }^{\mathrm{a}, \mathrm{c}}$ & one $3 \mathrm{~cm}^{2}$ grapefruit peel, one $3 \mathrm{~cm}^{2}$ grapefruit flesh \\
Passion fruit ${ }^{\mathrm{a}, \mathrm{c}}$ & one $2 \mathrm{~cm}^{2}$ piece of skin and four pips of fresh passion fruit \\
Banana $^{\mathrm{a}, \mathrm{c}}$ & one $3 \mathrm{~cm}^{2}$ piece of fresh banana (without the peel) \\
Stonefruit & one $3 \mathrm{~cm}^{2}$ piece of fresh yellow cling peach, 20 mL apricot juice (Liqui-Fruit) \\
Cooked vegetables & $2 \mathrm{~mL}$ asparagus brine (Koo), $5 \mathrm{~mL}$ green bean brine (Koo) \\
\hline${ }^{\mathrm{a}}$ These quantities were added to $100 \mathrm{~mL}$ of neutral white wine and soaked for 18 hours. \\
${ }^{\mathrm{b}}$ Standards were presented fresh in amber glass bottles covered with foil. \\
${ }^{\mathrm{c}}$ All fresh products were purchased from local grocers, Checkers, Spar or Woolworths.
\end{tabular}


Statistica 10 (Statsoft Inc., www.statsoft.com), followed by a post-hoc Fisher's least significant difference (LSD) analysis, to determine significant differences in the chemical and sensory analyses $(p<0.05)$. Principal component analysis (PCA) was performed with the same software for sensory data analysis.

\section{RESULTS AND DISCUSSION}

Wine fermentations followed similar performance in the assayed treatments, being completed within 16 days, with residual sugar levels lower than $4 \mathrm{~g} / \mathrm{L}$. The standard oenological parameters (alcohol, volatile acidity $(\mathrm{mg} / \mathrm{L})$, $\mathrm{pH}$, total acidity (mg/L) and residual sugar) showed nonsignificant differences between treatments (results not shown).

\section{GSH released from DYP}

The release of reduced GSH from DYP was performed in a synthetic wine as reported by Andujar-Ortiz et al. (2012). The amount of reduced GSH released from $0.4 \mathrm{~g} / \mathrm{L}$ of GSHrich inactivated yeast preparation into a model solution under our conditions was found to be $5.48 \pm 0.42 \mathrm{mg} / \mathrm{L}$. Based on this result, $5.5 \mathrm{mg} / \mathrm{L}$ of GSH was added to the juice in one of the studied treatments. Kritzinger et al. (2012) reported a GSH release of between 1.45 and $2.53 \mathrm{mg} / \mathrm{L}$ for a $0.3 \mathrm{~g} / \mathrm{L}$ addition of DYP. Moreover, the results observed in this study are close to those reported by Andujar-Ortiz et al. (2012), in which $0.4 \mathrm{~g} / \mathrm{L}$ of eight different DYPs were tested. The reduced GSH release was found to be between 2.03 and $0.46 \mathrm{mg} / \mathrm{L}$. The differences found in the levels of GSH could be attributed to variations in the manufacturing processes. The availability of different nitrogen sources and other nutrients during the growth of the yeast culture (AndujarOrtíz et al., 2012), or possible batch differences, could explain the reported results. Furthermore, Li et al. (2004) and Wen et al. (2004) reported cysteine level as a limiting factor for GSH biosynthesis. In addition, Tirelli et al. (2010) and Andujar-Ortiz et al. (2012) reported a decrease in the levels of GSH present in DYPs, possibly due to the thermal treatment involved in the drying process.

\section{GSH concentrations during alcoholic fermentation}

The assayed treatments presented different trends in GSH levels during alcoholic fermentation. Before GSH and/or DYP additions (ba), GSH concentrations in the juices ranged from 2.4 to $3.2 \mathrm{mg} / \mathrm{L}$ (Fig. 1), but these were non-significant. After additions (aa, Fig. 1), the treatments GSH 80, which was selected based on the highest GSH concentration reported in a South African grape juice (Du Toit et al., 2007), and DYP + GSH 80 showed the highest levels of GSH, whereas, as expected, the control (C) wines showed the lowest levels. After addition (aa), the GSH 5.5 and DYP treatments showed similar levels of GSH, with 8.8 and $8.3 \mathrm{mg} / \mathrm{L}$ respectively. The difference in GSH levels between the control (C) and the DYP treatment $(5.7 \mathrm{mg} / \mathrm{L})$ was consistent with the results reported by Andujar-Ortiz et al. (2012). During alcoholic fermentation, the GSH levels decreased until 50\% completion of the fermentation was reached, and from this point onwards an increase was observed until the end of the fermentation. Several authors have observed contradictory results, with either an increase (Park et al., 2000; Fracassetti et al., 2010; Kritzinger et al., 2013a) or a decrease in GSH concentrations (Du Toit et al., 2007; Coetzee et al., 2013) during alcoholic fermentation. The GSH 5.5 and DYP treatments showed similar levels of GSH during the alcoholic fermentation, with no significant differences at the end of this process (11.8 and $13.2 \mathrm{mg} / \mathrm{L}$ respectively). Moreover, the GSH 80 and DYP+GSH 80 wines showed similar concentrations (67.3 and $69.8 \mathrm{mg} / \mathrm{L}$ respectively), which were significantly higher when compared to the other treatments.

The GSH assimilation during alcoholic fermentation might be carried out by cellular transporters, which have already been characterised by Miyake et al. (1998) and Bourbouloux et al. (2000). GSH could be assimilated and secreted by yeast during alcoholic fermentation; therefore, the amount of GSH might be affected by factors such as yeast strain, oxygen level, initial GSH concentrations and nutriment status of the juice (Kritzinger et al., 2013b). Kritzinger et al. (2013b) found that the addition of glutathione-enriched inactive dry yeast preparations led to increased levels of $\mathrm{GSH}$ at the end of alcoholic fermentation. However, it is not clear whether these results are due to increases in GSH levels due to GSH contained in the DYP, GSH synthesis by the yeast from free amino acids, peptides, etc. in the DYP, or preferential uptake of nutrients supplied by the DYP over those supplied by native GSH (Kritzinger et al., 2013b). One of the aims of this study was to investigate whether increased GSH levels in the wine are due to the production of GSH from constituents in DYP, or simply due to the addition of GSH contained in the DYP. After addition (aa), the DYP additions led to increases in GSH levels in the juice, but this higher trend did not occur at the latter stages of alcoholic fermentation, with no significant differences between the DYP and corresponding GSH additions. This work could not provide a clear answer to this question, which requires further investigation.

\section{Volatile compounds}

Table 2 shows the levels of volatile compounds quantified in the Sauvignon blanc wines. Esters, fatty acids and higher alcohols have a fermentative origin, while terpenes and certain volatile thiols are classed as varietal aromas (Tominaga \& Dubourdieu, 2003; Swiegers at al., 2005; Polásková et al., 2008). Concentrations found in the wines made in this study are in accordance with previously reported research (Francis \& Newton, 2005; Benkwitz et al., 2012; Jouanneau et al., 2012). Moreover, differences were found for the aroma composition between the different wine treatments (Table 2). The volatile compounds ethyl butyrate, ethyl hexanoate, ethyl octanoate, ethyl decanoate, isoamyl acetate and 2-phenylethyl acetate were all found above their perception thresholds (p.t.) and were influenced to a different extent in some treatments compared to the control wines. The ethyl decanoate levels were also significantly higher in the DYP+GSH 80 wines compared to the control. Ethyl acetate levels were also increased by the DYP addition. Levels of hexyl acetate were increased in all the treatments - except the GSH80 treatment - when compared to the control. The increases in certain esters found in some of the treated wines could be related to the extra supplementation of nitrogenous 


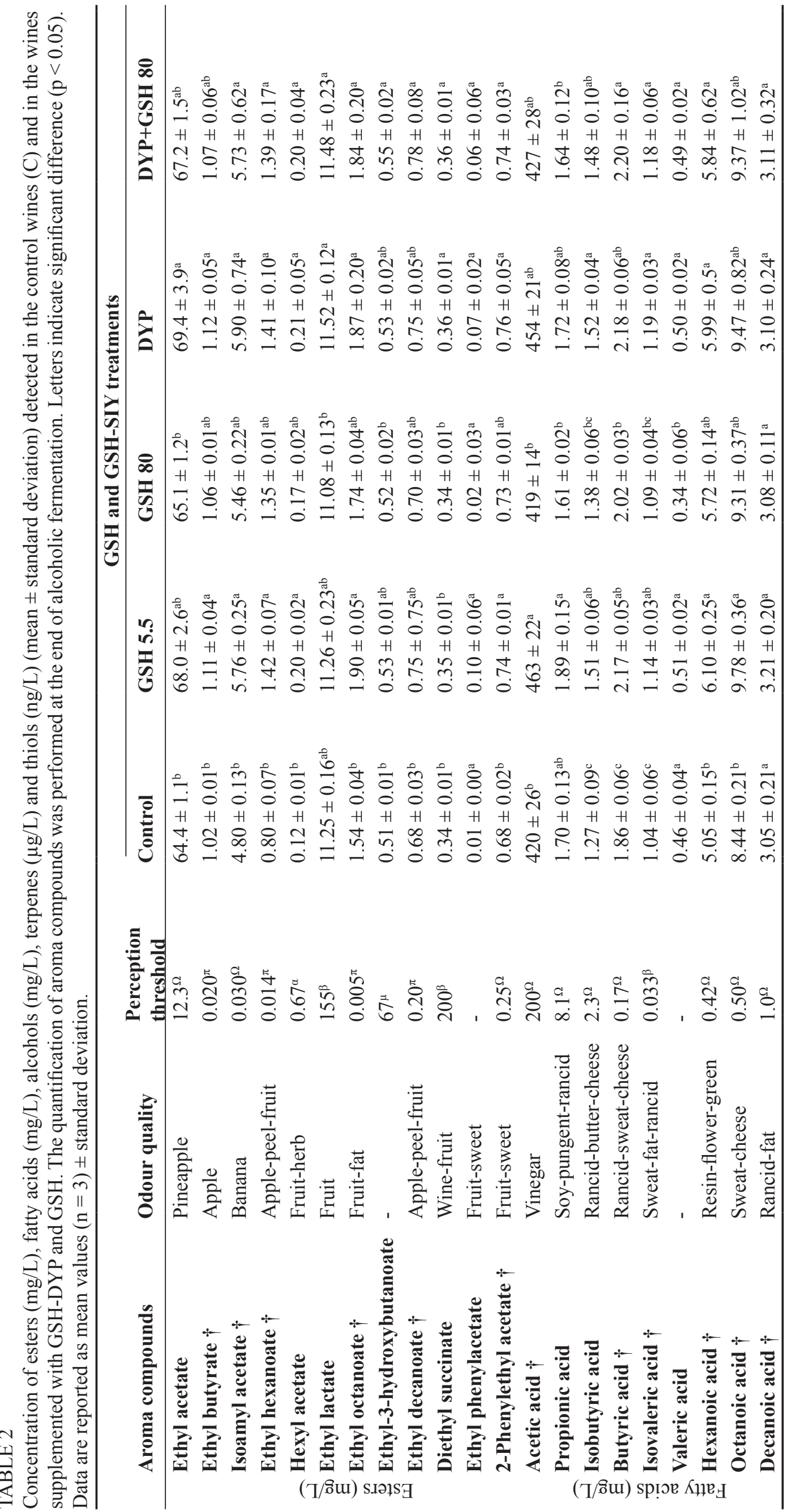




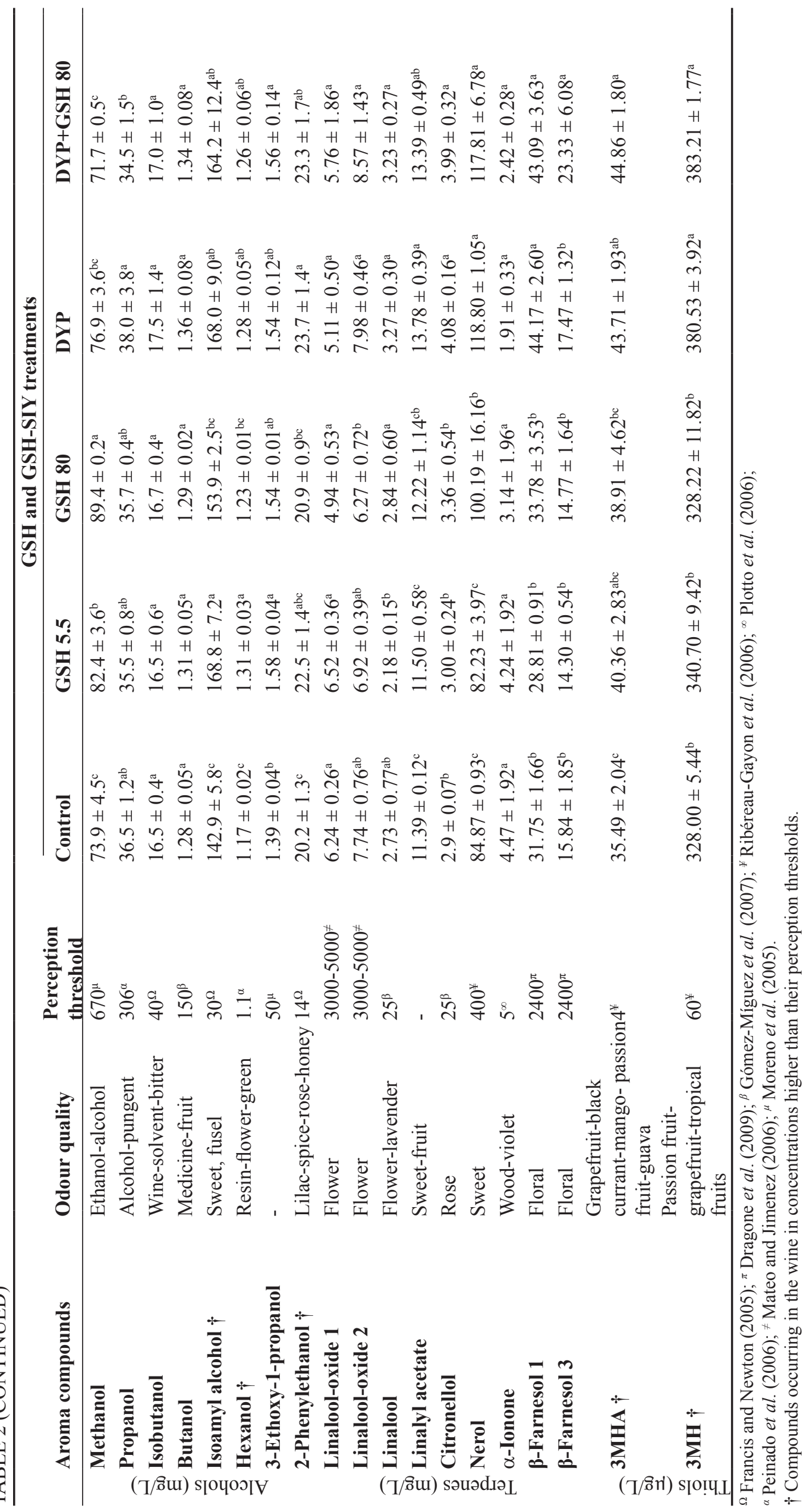




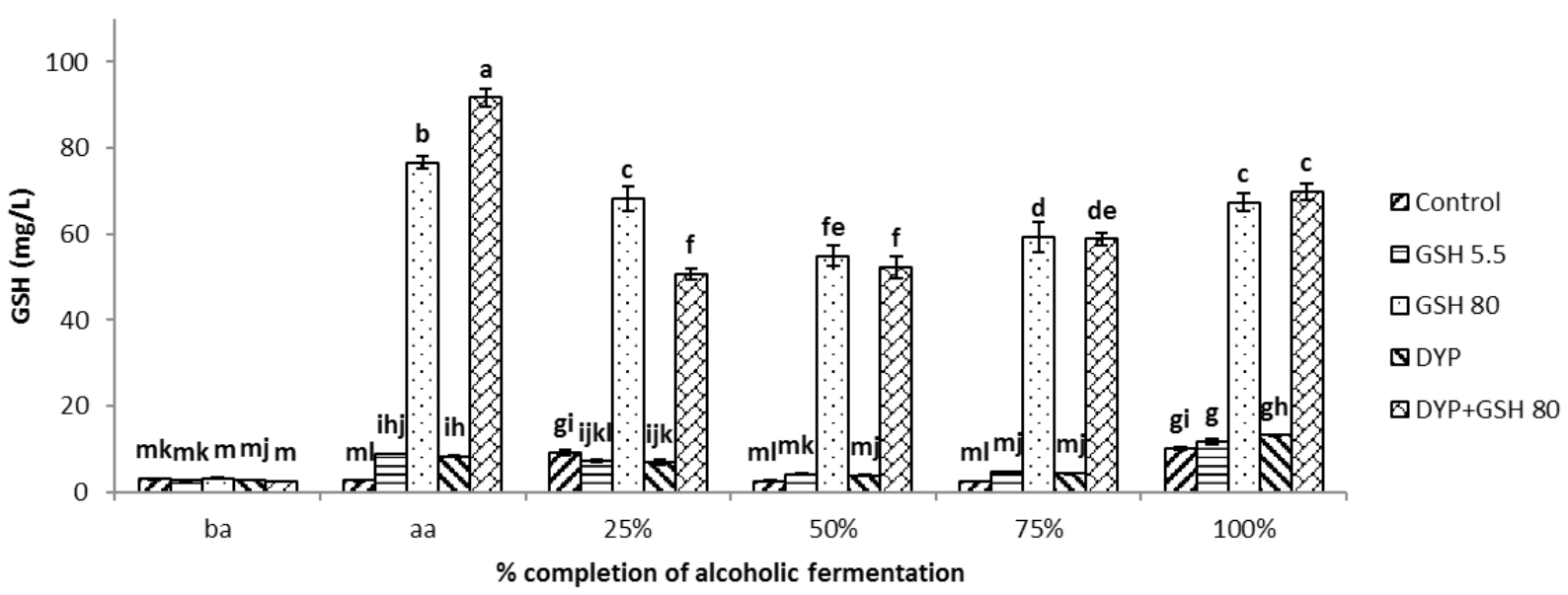

FIGURE 1

Extracellular GSH trend in Sauvignon blanc wine during alcoholic fermentation. Letters indicate significant difference $(\mathrm{p}<0.05)$. ba: before additions of GSH and/or DYP, aa: after additions of GSH and/or DYP. Mean values $(\mathrm{n}=3)$ and standard deviation (vertical bars) are reported.

compounds in DYP, as GSH and alpha amino acids released from GSH and/or DYP might have increased the production of these compounds during the alcoholic fermentation.

Fatty acids have been described as having fruity, fatty, cheese, sweat, butter and rancid notes (Francis \& Newton, 2005). The treatments also led to changes in the fatty acid concentrations compared to the control wines, depending on the treatment and compound investigated (Table 2). In the case of butyric acid, for instance, all GSH and DYP additions led to higher levels of this fatty acid compared to the control wines, with varying results observed for hexanoic, octanoic and isobutyric acids. Regarding hexanoic acid, significantly higher concentrations were found in the GSH 5.5, DYP and DYP+GSH 80 wines when compared to the control. Moreover, isovaleric acid showed higher levels in the DYP and DYP+GSH 80 compared to the GSH 5.5 wines, in which the levels were also significantly higher than in the control wines. Finally, variable results were observed for octanoic and valeric acids.

Higher alcohols and esters are formed during alcoholic fermentation and play an important role in wine flavour (Valero et al., 2002). The higher alcohols are characterised by the aromas of rose, spice, lilac, alcohol, ripe fruit resin, herbaceous and whiskey (Francis \& Newton, 2005). At concentrations above $400 \mathrm{mg} / \mathrm{L}$ they are considered as negative quality factors (Rapp \& Versini, 1991), while at low concentration (up to $300 \mathrm{mg} / \mathrm{L}$ ) they are thought to increase the aromatic complexity of the wine (Ribéreau-Gayon et al., 2006).

The amounts of total higher alcohols observed in this study ranged from $220 \mathrm{mg} / \mathrm{L}$ (C) to $251 \mathrm{mg} / \mathrm{L}$ (DYP). Hexanol, isoamyl alcohol and 2-phenylethanol were detected at concentrations higher than their perception thresholds, and at higher levels in the DYP-treated wines than those observed in the control wines. Hexanol and isoamyl alcohol levels were also significantly higher in the wines treated with GSH 5.5, DYP and DYP+GSH 80 than in the control wines. Moreover, the levels of 2-phenyl ethanol were significantly higher in DYP and DYP+GSH 80 when compared to the control wines. Interestingly, methanol levels were slightly higher in the wines made from juice to which GSH had been added at different levels (GSH 5.5 and GSH 80). Finally, no clear trends were observed in the assayed wines for propanol levels. Andújar-Ortiz et al. (2014) also found increased levels of isoamyl acetate, hexyl acetate, 2-phenylethyl acetate and certain long-chain ethyl esters, as well as hexanoic acids to which DYP had been added, which corroborates our results. Limited data is available on the effect of only GSH additions on ester, fatty acid and higher alcohol production during alcoholic fermentation, which this work investigated.

The monoterpene alcohols feature prominently in the aroma of many wine varieties, such as Muscat, Gewurztraminer and Weisser Riesling (Kritzinger et al., 2013a). Terpenes have been described as having rose, lavender, geranium, lychee and green notes (Francis \& Newton, 2005). Due to the oxidation phenomena during wine ageing, monoterpene alcohols, such as geraniol and linalool, decrease to form dihydric alcohols and terpene dioxides, which have higher perception threshold (Simpson, 1978; Simpson \& Miller, 1983). The volatile compound citronellol, the sesquiterpene $\beta$-farnesol 1 , linalyl acetate and nerol were significantly increased by DYP addition (DYP and DYP+GSH 80 treatments). Moreover, the levels of nerol were also significantly higher in the GSH 80 wines compared to the control and GSH 5.5 treatments. Other researchers have also found higher levels of certain terpenes in wines exposed to DYP treatments (Andujar-Ortiz et al., 2012; Rodríguez-Bencomo et al., 2014). As the wines in this study were analysed only three months after bottling, the anti-oxidant activities of DYP in preserving certain terpenes, as reported by Rodríguez-Bencomo et al. (2014), probably also had such an effect.

Sauvignon blanc wines are characterised by the presence of highly odorous thiol compounds, such as 4-mercapto-4methylpentan-2-one (4MMP), 4-mercapto-4-methylpentan2-ol (4MMPOH), 3-mercaptohexan-1-ol (3MH) and 
TABLE 3

Wine sensory data (out of 100) generated with descriptive analysis for the different treatments. Letters indicate significant differences $(\mathrm{p}<0.05)$.

\begin{tabular}{llllll}
\hline Sensory descriptor & C & GSH 5.5 & GSH 80 & DYP & DYP+80 GSH \\
\hline Cooked vegetable & $1.3 \pm 4.0^{\mathrm{a}}$ & $1.4 \pm 4.4^{\mathrm{a}}$ & $2.5 \pm 5.9^{\mathrm{a}}$ & $3.3 \pm 7.0^{\mathrm{a}}$ & $2.5 \pm 5.3^{\mathrm{a}}$ \\
Overall tropical & $35.7 \pm 14.8^{\mathrm{a}}$ & $43.6 \pm 12.2^{\mathrm{b}}$ & $47.7 \pm 12.7^{\mathrm{b}}$ & $56.7 \pm 10.1^{\mathrm{c}}$ & $56.2^{\mathrm{a}} \pm .5^{\mathrm{c}}$ \\
Canned tropical & $25.9 \pm 10.4^{\mathrm{a}}$ & $34.8 \pm 18.0^{\mathrm{b}}$ & $49.4 \pm 13.6^{\mathrm{c}}$ & $62.3 \pm 10.6^{\mathrm{d}}$ & $63.6 \pm 10.9^{\mathrm{d}}$ \\
Banana & $2.2 \pm 7.2^{\mathrm{a}}$ & $11.0 \pm 20.7^{\mathrm{b}}$ & $23.2 \pm 15.4^{\mathrm{c}}$ & $32.1 \pm 15.9^{\mathrm{d}}$ & $33.6 \pm 19.3^{\mathrm{d}}$ \\
Grapefruit & $26.3 \pm 18.4^{\mathrm{b}}$ & $30.1 \pm 18.9^{\mathrm{b}}$ & $12.1 \pm 15.6^{\mathrm{a}}$ & $11.7 \pm 9.8^{\mathrm{a}}$ & $15.7 \pm 15.4^{\mathrm{a}}$ \\
Green guava & $11.5 \pm 15.6^{\mathrm{b}}$ & $11.3 \pm 15.0^{\mathrm{b}}$ & $3.1 \pm 7.5^{\mathrm{a}}$ & $2.4 \pm 10.4^{\mathrm{a}}$ & $2.9 \pm 9.8^{\mathrm{a}}$ \\
Ripe guava & $1.0 \pm 3.9^{\mathrm{a}}$ & $5.0 \pm 13.0^{\mathrm{a}}$ & $12.8 \pm 16.2^{\mathrm{b}}$ & $19.6 \pm 15.6^{\mathrm{bc}}$ & $21.1 \pm 16.7^{\mathrm{c}}$ \\
Fresh pineapple & $36.7 \pm 15.3^{\mathrm{c}}$ & $29.53 \pm 19.9^{\mathrm{b}}$ & $6.3 \pm 17.3^{\mathrm{a}}$ & $0.0 \pm 0.0^{\mathrm{a}}$ & $1.2 \pm 5.0^{\mathrm{a}}$ \\
Canned pineapple & $0.8 \pm 4.6^{\mathrm{a}}$ & $11.8 \pm 22.2^{\mathrm{b}}$ & $29.5 \pm 19.5^{\mathrm{c}}$ & $41.4 \pm 15.4^{\mathrm{d}}$ & $39.4 \pm 17.1^{\mathrm{d}}$ \\
Passion fruit & $8.8 \pm 10.9^{\mathrm{bc}}$ & $11.5 \pm 9.8^{\mathrm{c}}$ & $3.0 \pm 6.9^{\mathrm{a}}$ & $4.2 \pm 6.7^{\mathrm{a}}$ & $5.9 \pm 9.8^{\mathrm{ab}}$ \\
Stone fruit & $4.1 \pm 9.4^{\mathrm{a}}$ & $6.5 \pm 12.4^{\mathrm{a}}$ & $14.73 \pm 10.0^{\mathrm{b}}$ & $19.6 \pm 11.5^{\mathrm{b}}$ & $14.3 \pm 11.6^{\mathrm{b}}$ \\
Fresh tropical & $74.1 \pm 10.4^{\mathrm{d}}$ & $65.2 \pm 18.0^{\mathrm{c}}$ & $50.6 \pm 13.6^{\mathrm{b}}$ & $37.7 \pm 10.6^{\mathrm{a}}$ & $36.4 \pm 10.9^{\mathrm{a}}$ \\
\hline
\end{tabular}

3-mercaptohexyl acetate (3MHA) (Darriet et al., 1995, Tominaga et al., 1998). 3MHA and 3MH are characterised by the mixed aroma of boxwood flowers, grapefruit and passion fruit (Tominaga et al., 2006). 3MHA (p.t. $4 \mathrm{ng} / \mathrm{L}$ ) and $3 \mathrm{MH}$ (p.t. $60 \mathrm{ng} / \mathrm{L}$ ) were always present at concentrations higher than their perception thresholds (Table 2). 3MH and 3MHA levels were significantly higher in the wines treated with the DYP. Surprisingly, the addition of GSH, even at relatively high concentrations of $80 \mathrm{mg} / \mathrm{L}$, did not increase the levels of these two important volatile thiols (Table 2). Glutathionerich inactivated yeast (DYPs) might stimulate the production of varietal thiols through the release of GSH or/and cysteine, although the former mechanism seems unlikely, since the additions of pure GSH did not lead to higher levels of these compounds. In addition, higher levels of glutamic acid released from DYP can lead to higher levels of 3MH (Šuklje et al., 2016). Contradictory results are found in the literature regarding the influence of GSH on thiol release, with some authors reporting an increase and others finding decreases (Patel et al., 2010; Roland et al., 2010; Makhotkina et al., 2014). Moreover, GSH has been used as an antioxidant at harvest, complementing a moderate $\mathrm{SO}_{2}$ addition. Higher thiol levels were observed, likely through an antioxidant effect (Makhotkina et al., 2014). Should GSH or the DYPs support a more reductive environment and greater $\mathrm{H}_{2} \mathrm{~S}$ levels, the production of $3 \mathrm{MH}$, and subsequently $3 \mathrm{MHA}$, might also be favoured, although this might be a minor route under normal winemaking conditions. However, Harsch et al. (2013) demonstrated that supplying grape juice with an external source of hydrogen sulphide drastically increases thiol formation in the finished wines.

GSH-enriched DYPs seemed to influence higher alcohols, fatty acids and ester levels, but this effect was less pronounced in the GSH-treated wines. These results point to a possible positive effect of GSH on these specific volatile compounds that might be related to its activity as a strong antioxidant. However, these mechanisms seem unlikely, as the addition of pure GSH at the same level as that found in the DYP, as well as a high addition $(80 \mathrm{mg} / \mathrm{L})$, often did not lead to the same increases. In the specific case of terpenes and volatile thiols, only DYP additions showed higher levels of these volatile compounds. Multiple reasons, such as the modification of by-products during fermentation, the release of volatiles from DYPs or the interaction of wine volatiles with compounds released by DYPs, could explain the differences observed in this study; and these need further investigation.

\section{Descriptive analysis}

In order to determine which sensory attributes were influenced by the addition of GSH or GSH-DYP, descriptive analysis was performed on the Sauvignon blanc wines. The results of the descriptive analysis are reported in Table 3. The statistical analysis (ANOVA) of each sensory descriptor showed significant differences between treatments (Table 3). The DYP and DYP+GSH 80 treatments were described by the panel as having higher levels of overall tropical, canned tropical, banana, stone fruit, ripe guava and canned pineapple attributes, whereas the GSH 80 sample presented significantly higher levels of the abovementioned compounds when compared against the control wines, but at lower intensities (except for the banana and stone fruit attributes) than those found for the DYP additions. The aroma of the control wine (C) was characterised by a sensory profile associated with fresh tropical and fresh pineapple notes. The GSH 5.5 wines had similar intensities of grapefruit, passion fruit and green guava compared to the control, and these intensities were higher than those observed in the other three treatments. The DYP additions thus influenced the volatile profile through increases of notes associated with ripe tropical fruits. On the other hand, adding $5.5 \mathrm{mg} / \mathrm{L} \mathrm{GSH}$ to the must before fermentation did not seem to be sufficient to alter the sensorial profile of the wine compared to that of the control wine. However, our sensory results also correlate with those of Andújar-Ortiz et al. (2014), who also found increases in banana character in the DYP-treated wines, with higher levels of peaches The sensorial differences observed in this study, along with those of Andújar-Ortiz et al. (2014) 
and Šklje et al. (2016), are thus probably not due to the GSH released from the DYP products, but due to the yeast forming different volatiles, brought about by the amino acids and peptides released from these products..

\section{CONCLUSION}

The addition of GSH or DYP to Sauvignon blanc grape must has been shown to increase the concentrations of certain volatile compounds, which included thiols and some monoterpenes in the case of the DYP-added treatments. The addition of DYP can also influence the sensory characteristics of the wine, leading to a change in the wine's aroma profile. The amount of GSH released into the wines when DYP was added, however, seems to be limited, and the increases in $\mathrm{GSH}$, volatile thiols and other compounds are probably due to a change in the chemical composition of the must. Nitrogen-based compounds and other components present in the DYP preparations are more likely responsible for the changes observed than the GSH added to the must due to DYP addition. However, this needs to be investigated further using other cultivars and DYP preparations.

\section{LITERATURE CITED}

Aguera, E., Samson, A., Caillé, S., Julien-Ortiz, A., Sieczkowski, N. \& Salmon, J.M., 2012. Apport de levures inactivées riches en glutathion en cours de fermentation alcoolique: un nouvel outil pour la protection des vins blancs et rosés contre 1'oxydation. Rev. Fr. Oenol. 250, 2-10.

Andújar-Ortiz, I., Chaya, C., Martín-Álvarez, P.J., Moreno-Arribas, M.V. \& Pozo-Bayón, M.A., 2014. Impact of using new commercial glutathione enriched inactive dry yeast oenological preparations on the aroma and sensory properties of wines. Int. J. Food Prop. 17, 987-1001.

Andujar-Ortiz, I., Pozo-Bayón, M.A., Moreno-Arribas, M.V., MartínÁlvarez, P.J. \& Rodríguez-Bencomo, J.J., 2012. Reversed-phase highperformance liquid chromatography-fluorescence detection for the analysis of glutathione and its precursor $\gamma$-glutamyl cysteine in wines and model wines supplemented with oenological inactive dry yeast preparations. Food Anal. Methods 5, 154-161.

Benkwitz, F., Tominaga, T., Kilmartin, P.A., Lund, M., Wohlers, C. \& Nicolau, L., 2012. Identifying the chemical composition related to the distinct flavour characteristics of New Zealand Sauvignon blanc wines. Am. J. Enol. Vitic. 63, 62-72.

Betés-Saura, C., Andrés-Lacueva, C. \& Lamuela-Raventós, R.M., 1996. Phenolics in white free run juices and wines from Penedès by highperformance liquid chromatography: Changes during vinification. J. Agric. Food Chem. 44, 3040-3046.

Blanchard, L., Darriet, P. \& Dubourdieu, D., 2004. Reactivity of 3-mercaptohexanol in red wine: Impact of oxygen, phenolic fractions, and sulfur dioxide. Am. J. Enol. Vitic. 55, 115-120.

Bourbouloux, A., Shahi, P., Chakladar, A., Delrot, S. \& Bachhawat, A.K., 2000. Hgtlp, a high affinity glutathione transporter from the yeast Saccharomyces cerevisiae. J. Biol. Chem. 275, 13259-13265.

Cheynier, V., Rigaud, J. \& Moutounet, M., 1990. Oxidation kinetics of transcaffeoyltartrate and its glutathione derivatives in grape musts. Phytochem. $29,1751-1753$

Cheynier, V., Souquet, J.M. \& Moutounet, M., 1989. Gluthatione content and gluthatione to hydroxycinnamic acid ratio in Vitis vinifera grapes and musts. Am. J. Enol. Vitic. 40, 320-324.

Coetzee, C. \& Du Toit, W.J., 2012. A comprehensive review on Sauvignon blanc aroma with a focus on certain positive volatile thiols. Food Res. Int 45, 287-298.
Coetzee, C., Lisjak, K., Nicolau, L., Kilmartin, P. \& Du Toit, W.J., 2013. Oxygen and sulfur dioxide additions to Sauvignon blanc must: Effect on must and wine composition. Flavour Frag. J. 28, 155-167.

Darriet, P., Tominaga, T., Lavigne-Cruege, V., Boidron, J.N. \& Dubourdieu, D., 1995. Identification of a powerful aromatic component of Vitis vinifera L. var. Sauvignon wines: 4-mercapto-4-methylpentan-2-one. Flavour Frag. J. 10, 385-392

Dragone, G., Mussatto, S.I., Oliveira, J.M. \& Teixeira J.A., 2009 Characterization of volatile compounds in an alcoholic beverage produced by whey fermentation. Food Chem. 112, 929-935.

Dubourdieu, D. \& Lavigne-Cruege, V., 2004. The role of glutathione on the aromatic evolution of dry white wine. Wine Internet Technical Journal, 02,2

Du Toit, W.J., Lisjak, K., Stander, M. \& Prevoo, D., 2007. Using LC-MS to assess glutathione levels in South African white grape juices and wines made with different levels of oxygen. J. Agric. Food Chem. 55, 2765-2769.

Elskens, M.T., Jaspers, C.J. \& Penninckx, M.J., 1991. Glutathione as an endogenous sulphur source in the yeast Saccharomyces cerevisiae. J. Gen. Microbiol. 137, 637-644.

Fedrizzi, B., Pardon, K.H., Sefton, M.A., Elsey, G.M. \& Jeffery, D.W., 2009. First identification of 4-S-glutathionyl-4-methylpentan-2-one, a potential precursor of 4-mercapto-4-methylpentan-2-one, in Sauvignon blanc juice. J. Agric. Food Chem. 57, 991-995.

Fracassetti, D., 2010. Investigation on cysteinyl thiol compounds from yeast affecting wine properties. Ph.D. Thesis, Technology and Biotechnology, University of Milan, Italy.

Francis, I.L. \& Newton, J.L., 2005. Determining wine aroma from compositional data. Aust. J. Grape Wine Res. 11, 114-126.

Gómez-Míguez, M.J., Cacho, J.F., Ferreira V., Vicario, I.M. \& Heredia, F.J., 2007. Volatile components of Zalema white wines. Food Chem. 100, 14641473.

Harsch, M.J., Benkwitz, F., Frost, A., Colonna-Ceccaldi, B., Gardner, R.C. \& Salmon, J.M., 2013. New precursor of 3-mercaptohexan-1-ol in grape juice: Thiol-forming potential and kinetics during early stages of must fermentation. J. Agric. Food Chem. 61, 3703-3713.

Jouanneau, S., Weaver, R.J., Nicolau, L., Herbst-Johnstone, M., Benkwitz, F. \& Kilmartin, P.A., 2012. Sub-regional survey of aroma compounds in Marlborough Sauvignon blanc wines. Aust. J. Grape Wine Res. 18, 329343.

Kritzinger, E.C., Bauer, F.F. \& Du Toit, W.J., 2013a. Role of glutathione in winemaking: A review. J. Agric. Food Chem. 61, 269-277.

Kritzinger, E.C., Bauer, F.F. \& Du Toit, W.J., 2013b. Influence of yeast strain, extended lees contact and nitrogen supplementation on glutathione concentrations in wine. Aust. J. Grape Wine Res. 19, 161-170.

Kritzinger, E.C., Stander, M. \& Du Toit, W.J., 2012. Assessment of glutathione levels in model solution and grape ferments supplemented with glutathione-rich inactivated dry yeast preparations using a novel UPLCMS/MS method. Food Addit. Contam. Part A. 30(1), 80-92.

Lavigne-Cruege, V. \& Dubourdieu, D., 2002. Role of glutathione on development of aroma defects in dry white wines. In 13th International Enology Symposium, Trogus, H., Gafner, J. and Sutterlin, A. Eds. International Association of Enology: Montpellier, France, pp 331-347

Lavigne-Cruege, V. \& Dubourdieu, D., 2004. Affinamento sulle fecce e freschezza dei vini bianchi. Vigne Vini 31, 58-66.

Lavigne-Cruege, V., Pons, A. \& Dubourdieu D., 2007. Assay of gluthatione in musts and wines using capillary electrophoresis and laser-induced fluorescence detection. Changes in concentration in dry wines during the alcoholic fermentation and aging. J. Chromatogr. A 1139, 130-135. 
Li, H., Guo, A. \& Wang H., 2008. Mechanisms of oxidative browning of wine. Food Chem. 108, 1-13.

Li, Y., Wei, G. \& Chen, J., 2004. Glutathione: A review on biotechnological production. Appl. Microbiol. Biotechnol. 66, 233-242.

Makhotkina, O., Araujo, L.D., Olejar, K., Herbst-Johnstone, M., Fedrizzi, B. \& Kilmartin, P.A., 2014. Aroma impact of ascorbic acid and glutathione additions to Sauvignon blanc at harvest to supplement sulphur dioxide. Am. J. Enol. Vitic. 65, 388-393.

Mateo, J.J. \& Jimenez, M., 2000. Monoterpenes in grape juice and wines. J. Chromatogr. A. 881, 557-567.

Miyake, T., Hazu, T., Yoshida, S., Kanayama, M., Tomochika, K., Shinoda, S. \& Ono, B., 1998. Glutathione transport systems of the budding yeast Saccharomyces cerevisiae. Biosci. Biotechnol. Biochem. 62, 1858-1864.

Moreno, J.A., Zea, L., Moyano, L. \& Medina, M., 2005. Aroma compounds as markers of the changes in sherry wines subjected to biological ageing. Food Control. 16, 333-338.

Oliveira, C.M., Ferreira A.C.S., De Freitas, V. \& Silva, A.M.S., 2011. Oxidation mechanisms occurring in wines. Food Res. Int. 44, 1115-1126.

OIV (Organisation of Vine and Wine), 2013. Resolution OIV-OENO 4592013. 11th OIV General Assembly, Bucharest, Romania.

OIV (Organisation of Vine and Wine), 2015. Resolutions OIV-OENO 4452015 and OIV-OENO 446-2015. 13th General Assembly, Mainz, Germany.

Park, S.K., Boulton, R.B. \& Noble, A.C., 2000. Formation of hydrogen sulphide and glutathione during fermentation of white grape musts. Am. J. Enol. Vitic. 51, 91-97.

Patel, P., Herbst-Johnstone, M., Lee, S.A., Gardner, R.C., Weaver, R., Nicolau, L. \& Kilmartin, P.A., 2010. Influence of juice pressing conditions on polyphenols, antioxidants and varietal aroma of Sauvignon blanc microferments. J. Agric. Food Chem. 58, 7280-7288.

Peinado, R.A., Mauricio, J.C. \& Moreno, J., 2006. Aromatic series in sherry wines with gluconic acid subjected to different biological aging conditions by Saccharomyces cerevisiae var. capensis. Food Chem. 94, 232-239.

Penninckx, M.A., 2002. An overview on glutathione in Saccharomyces versus non-conventional yeasts. FEMS Yeast Res. 2, 295-305.

Plotto, A., Barnes, K.W. \& Goodner, K.L., 2006. Specific anosmia observed for $\beta$-ionone, but not for $\alpha$-ionone: Significance for flavour research. J. Food Sci. 71, 401-406.

Polásková, P., Herszage J. \& Ebeler, S.E., 2008. Wine flavour: Chemistry in a glass. Chem. Soc. Rev. 37, 2478-2489.

Pozo-Bayón, M.A., Andújar-Ortiz, I. \& Moreno-Arribas, M.V., 2009. Scientific evidences beyond the application of inactive dry yeast preparations in winemaking. Food Res. Int. 42, 754-761.

Rapp, A. \& Versini, G., 1991. Influence of nitrogen compounds in grapes on aroma compounds of wine. In: Rantz, J. (ed.). Proc. Internat. Symp, Nitrogen in Grapes and Wines of the American Society for Enology and Viticulture, Month? 1991, Seattle, WA. pp. 156 - 164.

Ribéreau-Gayon, P., Glories, Y., Maujean, A. \& Dubourdieu, D., 2006 ( $\left.2^{\text {nd }} \mathrm{ed}\right)$. Handbook of enology: The chemistry of wine stabilization and treatments, vol 2. John Wiley \& Sons Ltd, Chichester, UK.
Rigaud, J., Cheynier, V., Souquet, J.M. \& Moutounet, M., 1991. Influence of must composition on phenolic oxidation kinetics. J. Sci. Food Agric. 57, $55-63$.

Rodríguez-Bencomo, J.J., Andújar-Ortiz, I., Moreno-Arribas, M.V., Simó, C., González, J., Chana, A., Dávalos, J. \& Pozo-Bayón, M.A., 2014. Impact of glutathione-rich inactivated dry yeast preparation on the stability of terpenes during model wine aging. J. Agric. Food Chem. 62, 1373-1383.

Roland, A., Vialaret, J., Razungles, A., Rigou, P. \& Schneider, R., 2010. Evolution of S-cysteinylated and S-glutathionylated thiol precursors during oxidation of melon B. and Sauvignon blanc musts. J. Agric. Food Chem. $58,4406-4413$

Simpson, R.F., 1978. Aroma and compositional changes in wine with oxidation, storage and ageing. Vitis 17, 274-287.

Simpson, R.F. \& Miller, G.C., 1983. Aroma composition of aged Riesling wine. Vitis. 22, 51-63.

Šuklje, K., Antalick, G., Buica, A., Coetzee, Z.A., Brand, J., Schmidtke, L.M. \& Vivier, M.A., 2016. Inactive dry yeast application on grapes modify Sauvignon blanc wine aroma. Food Chem. 197, 1073-1084.

Swiegers, J.H., Bartowsky, E.J., Henschke, P.A. \& Pretorius, I.S., 2005. Yeast and bacteria modulation of wine aroma and flavour. Aust. J. Grape Wine Res. 11, 139-173.

Tirelli, A., Fracassetti, D. \& De Noni, I., 2010. Determination of reduced cysteine in oenological cell wall fractions of Saccharomyces cerevisiae. J. Agric. Food Chem. 58, 4565-4570.

Tomic, O., Luciano, G., Nilsen, A., Hyldig, G., Lorensen, K. \& Naes, T., 2010. Analysing sensory panel performance in a proficiency test using the PanelCheck software. Eur. Food Res. Technol. 230(3), 497-511.

Tominaga, T. \& Dubourdieu, D., 2003. Recent advance of aroma research of wines made from non-aromatic grape varieties - an example of Sauvignon blanc in Bordeaux. J. Brew. Soc. Jpn. (Nippon Jozokyokai Shi) 98, 628-637.

Tominaga, T., Furrer, A., Henry, R. \& Dubourdieu, D., 1998. Identification of new volatile thiols in the aroma of Vitis vinifera L. var. Sauvignon blanc wines. Flavour Frag. J. 13, 159-162.

Tominaga, T., Niclass, Y., Frérot, E. \& Dubourdieu, D., 2006. Stereoisomeric distribution of 3-mercaptohexan-1-ol and 3-mercaptohexyl acetate in dry and sweet white wines made from Vitis vinifera (var. Sauvignon blanc and Semillon). J. Agric. Food Chem. 54, 7251-7255.

Ugliano, M., Kwiatkowski, M., Vidal, S., Capone D., Siebert, T., Dieval, J.B., Aagaard, O. \& Waters, E.J., 2011. Evolution of 3-mercatohexanol, hydrogen sulfide, and methyl mercaptan during bottle storage of Sauvignon blanc wines: effect of glutathione, copper, oxygen exposure, and closurederived oxygen. J. Agric. Food Chem. 59, 2564-2572.

Valero, E., Moyano, L., Millan, M.C., Medina, M. \& Ortega, J.M., 2002. Higher alcohols and esters production by Saccharomyces cerevisiae. Influence of the initial oxygenation of the grape must. Food Chem. 78, 5761.

Wen, S., Zhang, T. \& Tan, T., 2004. Utilization of amino acids to enhance glutathione production in Saccharomyces cerevisiae. Enzyme Microb. Technol. 35, 501-507. 